\section{Annual cost of bipolar disorder to UK society}

ROBEN DAS GUPTA and JULIAN F. GUEST

\author{
Background The socio-economic \\ impact of bipolar disorder in the UK is \\ unknown.
}

\begin{abstract}
Aims To estimate the annual socioeconomic burden imposed by bipolar disorder on UK society.
\end{abstract}

Method The annual cost of resource use attributable to managing bipolar disorder was calculated. Indirect societal costs were also calculated.

\section{Results The annual National Health} Service (NHS) cost of managing bipolar disorder was estimated to be $€ 199$ million, of which hospital admissions accounted for $35 \%$. The annual direct non-health-care cost was estimated to be $£ 86$ million annually and the indirect societal cost was estimated to be $£ 1770$ million annually.

\section{Conclusions The annual cost to UK} society attributable to bipolar disorder was estimated to be $£ 2$ billion at 1999/ 2000 prices (estimated 297000 people with the disorder). Ten per cent of this cost is attributable to $\mathrm{NHS}$ resource use, $4 \%$ to non-health-care resource use and $86 \%$ to indirect costs.

\section{Declaration of interest This study} was funded by a grant from Janssen-Cilag, Saunderton, UK
Bipolar disorder is a common illness characterised by recurrent episodes of mania and major depression. The lifetime prevalence of bipolar disorder is between $1 \%$ and 2\% (Bebbington \& Ramana, 1995). Moreover, bipolar disorder is often associated with other mental disorders, particularly alcoholism and substance misuse (Regier et al, 1990). Bipolar disorder places a substantial burden on primary and secondary health-care sectors as well as other statutory services (Office for National Statistics, 1995; Onyett et al, 1995); however, the socio-economic impact of bipolar disorder on UK society is unknown. Against this background we estimated the annual cost imposed by bipolar disorder on UK society.

\section{METHOD}

\section{Perspective}

This evaluation estimated:

(a) the annual costs of managing bipolar disorder from the perspective of the National Health Service (NHS);

(b) the annual costs resulting from bipolar disorder borne by other statutory agencies, such as local authorities and the criminal justice system; and

(c) the indirect annual costs to society due to unemployment, absenteeism from work and premature mortality.

\section{Primary care resource use}

The DIN-link database contains information on 0.9 million live patients managed by approximately 360 general practitioners (GPs) in 100 nationally distributed general practices (using AAH Meditel System 5 clinical software, version 5.7.x for UNIX; now System 5, Torex Health, Bromsgrove, Worcestershire, UK). The database was interrogated to obtain the annual amount of primary care resource use (i.e. GP consultations, GP-prescribed drugs and
GP-initiated diagnostic tests) between 1 January 1998 and 31 December 1998 attributable to managing bipolar disorder. Patients were included if they had a note entry of one of the following Read codes, together with an addition or amendment to their case notes in the study year, indicating that they were still registered with their GP: hypomania/mania (E221); other manicdepressive psychoses (E22Z); affective psychoses (E22). The resource use estimates derived from the DIN-link database were extrapolated to the whole of the NHS by multiplying by a factor of 75 , which takes into account the size of the data-set population relative to that of the whole UK and the relative underrecording of certain data items when the database is cross-referenced against other sources (Martin, 1995).

\section{Secondary care in-patient resource use}

Hospital in-patient data were based on the IBM Hospital Episode Statistics database, which contains information compiled from the statutory returns from the 300 trusts in England. The database was interrogated to obtain the annual number of hospital episodes attributable to bipolar disorder in accordance with the diagnostic codes of ICD-10 (World Health Organization, 1992) (i.e. F31.0-F31.9 for $1995 / 96$ to 1997/98). Patients were included in the data-set if they had a primary diagnosis of bipolar disorder between 1 April 1995 and 31 March 1998. Results were extrapolated to the whole UK by multiplying by 1.2 (i.e. the ratio of the population of the UK to that of England).

\section{Other health care resource use}

Published sources were used to provide information on resource utilisation by psychiatric patients using NHS day hospitals (Department of Health, 1999a), out-patient services (Department of Health, 1999b), community mental health teams (CMHTs; Onyett et al, 1995) and special (high-security) hospitals (Department of Health, 2000a,c). This was supplemented with information obtained from interviews with ten NHS consultant psychiatrists who had experience of people with bipolar disorder.

\section{Personal social service resource use and the criminal justice system}

Data were obtained on resource utilisation by people with bipolar disorder using 
residential services (D. Chisholm, personal communication, 1999), the criminal justice system (Stationery Office, 2000a) and nonNHS day care facilities (Department of Health, 1998), the latter being supplemented with information obtained from telephone interviews with managers at seven non-NHS day care facilities.

\section{Resource costs}

Unit resource costs were obtained (D. Chisholm, personal communication, 1999; Netten et al, 1999; Haymarket Publications, 2000; Stationery Office, $2000 \mathrm{~b}$ ) and, where necessary, uprated to 1999/2000 prices using the Health Service Inflation Index (Netten et al, 1999). By assigning these costs to the resource use estimates, the annual direct cost attributable to bipolar disorder was calculated at 1999/2000 prices.

\section{Indirect resource use and costs}

The indirect cost arising from excess unemployment (Gareth Hill et al, 1996), absenteeism from work (Lepine et al, 1997) and suicide (Sharma \& Markar, 1994) among individuals with bipolar disorder was estimated using the human capital approach (Drummond et al, 1998), by applying the current annual average wage (Office for National Statistics, 2000) to the estimated number of people with bipolar disorder absent from work as a result of morbidity and mortality. A $6 \%$ annual discount rate was applied to the indirect costs of unemployment arising from people with bipolar disorder who commit suicide in the study year and, therefore, who are absent from the workforce in subsequent years.

\section{Sensitivity analysis}

Univariate sensitivity analyses tested the robustness of the study results to changes in resource use activity affecting healthcare, non-health-care and indirect costs.

\section{RESULTS}

\section{National Health Service resource use}

\section{The DIN-link database}

The DIN-link database contained data on 1807 patients with bipolar disorder in 1998, equivalent to approximately 136000 people with bipolar disorder being registered with a GP during that year. The mean age of people with bipolar disorder in the DIN-link data-set was 54 years. Of these, $62 \%$ were female and $38 \%$ were male. Additionally, patients aged $<21$ years accounted for $<1 \%$ of the total number of patients in the DIN-link data-set.

\section{GP consultations}

Based on all the people with bipolar disorder in the DIN-link database, it was estimated that there were 315000 GP consultations attributable to bipolar disorder during 1998. Hence, the annual cost of GP consultations attributable to bipolar disorder was estimated to be $£ 5.2$ million.

\section{GP-prescribed drugs}

Fifty-eight per cent of patients in the DINlink data-set received medication for bipolar disorder prescribed by their GP during 1998. This corresponds to an estimated 79125 patients receiving approximately 1.2 million GP-prescribed items during the study year (Table 1). These GP-prescribed drugs cost $£ 8.5$ million.

The mean annual cost of GP-prescribed medication was $£ 107$ per patient receiving medication. This corresponds to a mean annual cost of $£ 249$ per GP and $£ 809$ per general practice for medication for bipolar disorder.

\section{GP-initiated tests}

People with bipolar disorder undergo a mean 111000 tests per year. These include blood drug levels, biochemistry tests, thyroid function tests and haematology tests, costing the NHS $£ 1.2$ million annually.

\section{In-patient episodes}

Between 1 April 1997 and 31 March 1998 there were 12400 annual hospital episodes for bipolar disorder in the UK, costing $£ 69$ million. These episodes accounted for $4 \%$ of the 290019 annual episodes for mental health (Department of Health, 2000a). From the interviews it was estimated that about $30 \%$ of these episodes would result in a patient being transported to a hospital by ambulance, costing the NHS $£ 670000$ annually. Table 2 summarises these data, stratified by different specialities.

Table 2 shows that $86 \%$ and $10 \%$ of episodes are admitted to mental illness beds and old age psychiatry beds, respectively. Furthermore, mental illness and old age psychiatry accounted for $85 \%$ and $11 \%$, respectively, of the costs of hospital care for bipolar disorder.

Forty-four per cent of the hospitalisation costs attributable to bipolar disorder were due to patients suffering from either mania or hypomania without psychotic symptoms, $27 \%$ to patients suffering from depression without psychotic symptoms, $16 \%$ to those suffering from mania with psychotic symptoms, $6 \%$ to patients suffering from depression with psychotic symptoms, $8 \%$ to those with a mixed episode, $3 \%$ to those in remission and $2 \%$ to other bipolar disorders.

The estimated mean annual number of hospital in-patient episodes per person with

Table I Annual number and corresponding cost of general practitioner-prescribed drugs for bipolar disorder

\begin{tabular}{lcc}
\hline Drug category & $\begin{array}{c}\text { Annual number }(\% \text { of total) } \\
\text { prescriptions }\left(\times 10^{3}\right)\end{array}$ & $\begin{array}{c}\text { Annual cost (\% of total) } \\
\text { prescriptions }\left( \pm \times 10^{3}\right)\end{array}$ \\
\hline Anti-Parkinsonians & $93(8 \%)$ & $236(3 \%)$ \\
Anxiolytics & $98(8 \%)$ & $103(1 \%)$ \\
Atypical antipsychotics & $16 \quad(1 \%)$ & $999(12 \%)$ \\
Carbamazepine & $58(5 \%)$ & $234(3 \%)$ \\
Hypnotics & $90 \quad(7 \%)$ & $285(3 \%)$ \\
Lithium & $239(20 \%)$ & $854(10 \%)$ \\
Non-SSRI antidepressants & $184(15 \%)$ & $1834(22 \%)$ \\
Sodium valproate & $32 \quad(3 \%)$ & $279(3 \%)$ \\
SSRI antidepressants & $128(11 \%)$ & $2385(28 \%)$ \\
Thyroxine & $6(<1 \%)$ & $7(<1 \%)$ \\
Typical antipsychotics & $268(22 \%)$ & $1249(15 \%)$ \\
Total & 1213 & 8466 \\
\hline
\end{tabular}

SSRI, selective serotonin reuptake inhibitor. 
Table 2 Annual number of hospital episodes and corresponding costs attributable to bipolar disorder

\begin{tabular}{|c|c|c|c|}
\hline Speciality & $\begin{array}{l}\text { Annual number } \\
\text { (\% of total) } \\
\text { hospital } \\
\text { episodes }\left(\times 10^{3}\right)\end{array}$ & $\begin{array}{c}\text { Annual cost } \\
\text { (\% of total) } \\
\text { hospital } \\
\text { episodes ( } \notin \text { million) }\end{array}$ & $\begin{array}{c}\text { Mean } \\
\text { length of } \\
\text { stay (days) }\end{array}$ \\
\hline Child and adolescent psychiatry & $33(<0.5 \%)$ & $0.8 \quad(1 \%)$ & 92 \\
\hline Forensic psychiatry & 69 (1\%) & I.3 (2\%) & 71 \\
\hline General medicine & 67 (1\%) & $0.1 \quad(<0.5 \%)$ & 5 \\
\hline Geriatric medicine & 47 (<0.5\%) & $0.1 \quad(<0.5 \%)$ & 22 \\
\hline Learning disability & 65 (1\%) & $0.5(I \%)$ & 51 \\
\hline Mental illness & 10652 (86\%) & $58.9(85 \%)$ & 38 \\
\hline Not known & 160 (1\%) & $0.4(1 \%)$ & 15 \\
\hline Old age psychiatry & 1264 (10\%) & $7.4(11 \%)$ & 49 \\
\hline Total & 12358 & 69.4 & 39 \\
\hline Ambulance journeys & 3813 & 0.7 & \\
\hline $\begin{array}{c}\text { Total annual cost of episodes } \\
\text { plus ambulance journeys }\end{array}$ & & 70.1 & \\
\hline
\end{tabular}

bipolar disorder was greater among the 25to 34-year age group, at seven episodes per year per 100 patients (equivalent to almost two-thirds of all the in-patient episodes), and was seven times greater than the annual number of episodes per patient in the $<16$ - and $>84$-year age groups. Generally, the annual number of hospital inpatient episodes per patient decreased with age among patients over 34 years of age. Additionally, the percentage of episodes associated with manic and hypomanic symptoms decreased with age. Conversely, proportionally more episodes were associated with depressive symptoms as patients' age increased.

\section{Out-patient and ward attendances}

Approximately 2 million annual psychiatric out-patient attendances are conducted under the auspices of mental illness and psychiatry of old age in the UK (Department of Health, 1999b), of which $14 \%$ was estimated to be because of bipolar disorder. Hence, it was estimated that a mean 277000 attendances a year are attributable to bipolar disorder, costing $£ 28.5$ million.

There are a mean 96000 annual psychiatric ward attendances in the UK (Department of Health, 1999b), of which $5 \%$ was estimated to be because of bipolar disorder. This suggests that there are a mean 5000 attendances a year attributable to bipolar disorder, costing $£ 0.5$ million.

\section{NHS day hospital attendances}

There are approximately 4.6 million attendances at psychiatric day hospitals annually in the UK (Department of Health, 1999a), of which $10 \%$ was estimated to be because of bipolar disorder. This corresponds to about 459000 attendances a year, costing $£ 28.9$ million.

\section{Special hospitals}

The approximate 1350 beds managed by the three high-security hospital authorities in the UK cost the NHS $£ 135.2$ million in 1999/2000 (Department of Health, 2000a). Based on data from a study of admissions to one special hospital in 1987/88 (Gunn et al, 1991), this analysis assumed that $2 \%$ of in-patients are admitted because of bipolar disorder, costing the NHS an estimated $£ 2.7$ million in $1999 / 2000$.

\section{Total annual NHS cost}

The total annual health-care cost attributable to managing bipolar disorder was estimated to be $£ 199$ million (Table 3 ).

\section{Residential care}

People with bipolar disorder were estimated to occupy 4822 places in residential accommodation, costing $£ 67.8$ million. Table 4 summarises these data, stratified by home type.

\section{Non-NHS day care attendances}

There are approximately 4.7 million attendances annually at non-NHS day care facilities in the UK by people with a mental illness (Department of Health, 1998), of which $16 \%$ was estimated to be because
Table 3 Annual National Health Service (NHS) costs attributable to bipolar disorder

Community mental health team contacts
The annual cost of CMHTs in the UK was to be because of bipolar disorder, corresponding to an annual cost of $£ 53.2$ million.

\begin{tabular}{lcc}
\hline Resource category & $\begin{array}{c}\text { Annual cost associated with } \\
\text { bipolar disorder }(£ \text { million) }\end{array}$ & $\begin{array}{c}\text { Percentage of annual general } \\
\text { psychiatric NHS cost }\end{array}$ \\
\hline Hospital admissions & $69.4(58.9)^{\prime}$ & $6 \%$ \\
Community mental health care & 53.2 & $14 \%$ \\
Out-patient attendances & 28.5 & $14 \%$ \\
Ward attendances & 0.5 & $5 \%$ \\
Day hospital attendances & 28.9 & $10 \%$ \\
GP-prescribed drugs & 8.5 & $<1 \%$ \\
GP consultations & 5.2 & Unknown \\
Special hospitals & 2.7 & $2 \%$ \\
GP-initiated tests & 1.2 & Unknown \\
Ambulance transport & 0.7 & Unknown \\
Total cost & 198.7 & \\
\hline
\end{tabular}

I. The cost in parentheses refers to the cost of admissions under the general psychiatric speciality. GP, general practitioner. 
Table 4 Residential care in the UK for people with bipolar disorder

\begin{tabular}{lcc}
\hline Home type & $\begin{array}{c}\text { Annual number (\% of total) places in } \\
\text { residential accommodation }\end{array}$ & $\begin{array}{c}\text { Annual cost (\% of total) residential } \\
\text { accommodation ( } £ \text { million) }\end{array}$ \\
\hline Group homes & $858(18 \%)$ & $6.1(9 \%)$ \\
Low-level hostels & $572(12 \%)$ & $5.0(7 \%)$ \\
Mid-level hostels & $981(20 \%)$ & $13.8(20 \%)$ \\
High-level hostels & $1839(38 \%)$ & $32.7(48 \%)$ \\
Small-scale hostels & $572(12 \%)$ & $10.2(15 \%)$ \\
Total & 4822 & 67.8 \\
\hline
\end{tabular}

of bipolar disorder. This corresponds to an estimated 754000 attendances a year, costing $£ 18.1$ million.

\section{Criminal justice system}

We were unable to find any published evidence that the incidence of either imprisonment or people on remand was higher among those with bipolar disorder than in the general population. Therefore, this analysis assumed that the cost incurred by the criminal justice system attributable specifically to bipolar disorder is zero.

\section{Indirect societal costs}

Indirect costs due to excess unemployment among people with bipolar disorder

The prevalence of bipolar disorder in the UK was estimated to be $0.5 \%$ (Bebbington \& Ramana, 1995), which is similar to the lifetime risk and annual prevalence rates and equates to approximately 297000 people with bipolar disorder in the UK annually. The unemployment rate among people with bipolar disorder was estimated to be $46 \%$, of whom $60 \%$ are available for work (Gareth Hill et al, 1996). This compared with an unemployment rate among the general population in the UK in 1999/2000 of 3\% (Office for National Statistics, 2000). Hence, an excess of

Table 5 Total annual societal cost attributable to bipolar disorder

\begin{tabular}{lr}
\hline Resource category & $\begin{array}{r}\text { Cost (\% of total) } \\
(£ \text { million })\end{array}$ \\
\hline Direct health-care costs & $199(10 \%)$ \\
Direct non-health-care costs & $86(4 \%)$ \\
Indirect costs & $1770(86 \%)$ \\
Total societal cost & 2055 \\
\hline
\end{tabular}

\section{Indirect costs due to suicide}

The annual incidence of bipolar disorder is $0.009 \%$ and $0.0096 \%$ for males and females, respectively (Bebbington \& Ramana, 1995). Hence, there are 4454 new cases of bipolar disorder diagnosed in the UK annually. The suicide rate among people with bipolar disorder is $1.5 \%$ annually for the first 10 years following diagnosis (Sharma \& Markar, 1994). This equates to an excess of 640 suicides because of bipolar disorder annually, with an associated indirect cost of $£ 179$ million undiscounted or $£ 109$ million discounted.
76500 people annually are unemployed as a result of having bipolar disorder. Therefore, the annual indirect cost due to excess unemployment among people with bipolar disorder was estimated to be $£ 1510$ million at $1999 / 2000$ prices.

Indirect costs due to absenteeism from work among people with bipolar disorder

The rate of excess absenteeism from work among those with major depression compared with those without depression was estimated to be about 9 days over a 6 month period in the UK (Lepine et al, 1997). Assuming that all of these subjects were in full-time employment, this suggests an excess absenteeism rate of $8 \%$. By assuming comparable absenteeism from work among the UK's estimated 96300 people with bipolar disorder who are employed (Kind \& Sorensen, 1993), the associated indirect cost would be $£ 152$ million per year at 1999/2000 prices.

\section{Indirect costs due to carers}

A review of the published literature did not identify any evidence that there was a higher unemployment rate among carers than the general population; therefore, it was estimated that there are no indirect costs specifically attributable to carers of people with bipolar disorder.

\section{Total annual societal cost of bipolar disorder}

The total annual societal cost of bipolar disorder in 297000 people was estimated to be $£ 2055$ million annually (Table 5) or approximately $£ 6919$ per person with bipolar disorder.

\section{Sensitivity analyses}

Health care costs

Sensitivity analyses (Table 6) showed that doubling the annual number of in-patient
Table 6 Sensitivity analyses on National Health Service resource categories

\begin{tabular}{|c|c|}
\hline Scenario & $\begin{array}{l}\text { Range of annual NHS cost } \\
\qquad(£ \text { million })\end{array}$ \\
\hline $\begin{array}{l}\text { Annual number of GP consultations, GP-initiated tests and GP-prescribed } \\
\text { drugs is reduced by } 50 \% \text { and increased by } 100 \% \text { above/below baseline }\end{array}$ & $|9|-2 \mid 4$ \\
\hline $\begin{array}{l}\text { Annual number of hospital in-patient episodes is reduced by } 50 \% \text { and } \\
\text { increased by } 100 \% \text { above/below baseline }\end{array}$ & $164-269$ \\
\hline $\begin{array}{l}\text { Annual number of out-patient and ward attendances is reduced by } 50 \% \\
\text { and increased by } 100 \% \text { above/below baseline }\end{array}$ & $185-227$ \\
\hline $\begin{array}{l}\text { Annual number of } \mathrm{CMHT} \text { contacts is reduced by } 50 \% \text { and increased } \\
\text { by } 100 \% \text { above/below baseline }\end{array}$ & $172-252$ \\
\hline $\begin{array}{l}\text { Annual number of day hospital attendances is reduced by } 50 \% \\
\text { and increased by } 100 \% \text { above/below baseline }\end{array}$ & $184-228$ \\
\hline $\begin{array}{l}\text { Annual number of in-patients in special hospitals is reduced by } 50 \% \\
\text { and increased by } 100 \% \text { above/below baseline }\end{array}$ & $198-202$ \\
\hline
\end{tabular}

GP, general practitioner; CMHT, community mental health team. 
Table 7 Sensitivity analyses on non-health-care resource categories

\begin{tabular}{lc}
\hline Scenario & $\begin{array}{c}\text { Range of annual } \\
\text { non-health-care } \\
\text { direct cost ( } £ \text { million) }\end{array}$ \\
\hline $\begin{array}{l}\text { Annual number of residential places is reduced by 50\% } \\
\text { and increased by 100\% above/below baseline }\end{array}$ & $52-154$ \\
$\begin{array}{l}\text { Annual number of non-NHS day care attendances is reduced by 50\% } \\
\text { and increased by 100\% above/below baseline }\end{array}$ & $77-104$ \\
$\begin{array}{l}\text { Use of the criminal justice system by people with bipolar disorder is half that } \\
\text { for the general population and double that for the general population }\end{array}$ & $47-164$ \\
\hline
\end{tabular}

Table 8 Sensitivity analyses on indirect costs

\begin{tabular}{lc}
\hline Scenario & $\begin{array}{c}\text { Range of annual indirect } \\
\text { cost ( } £ \text { million) }\end{array}$ \\
\hline $\begin{array}{l}\text { Annual number of unemployed people with bipolar disorder is reduced } \\
\text { by } 50 \% \text { and increased by } 100 \% \text { above/below baseline }\end{array}$ & $1016-3280$ \\
$\begin{array}{l}\text { Excess rate of absenteeism from work among people with bipolar disorder } \\
\text { is reduced by } 50 \% \text { and increased by } 100 \% \text { above/below baseline }\end{array}$ & $1695-1922$ \\
$\begin{array}{l}\text { Annual number of suicides attributable to bipolar disorder is reduced } \\
\text { by } 50 \% \text { and increased by } 100 \% \text { above/below baseline }\end{array}$ & $1716-1880$ \\
\hline
\end{tabular}

episodes and CMHT contacts would increase the annual NHS cost of managing bipolar disorder by $35 \%$ and $27 \%$, respectively. Conversely, halving the annual number of in-patient episodes and CMHT contacts would reduce the annual NHS cost of managing bipolar disorder by $18 \%$ and $13 \%$, respectively. However, the annual NHS cost is not sensitive to changes in the use of any other health care resource.

\section{Non-health-care direct costs}

Sensitivity analyses (Table 7) showed that doubling of the annual number of residential places would increase the annual non-health-care cost of managing bipolar disorder by $79 \%$. Conversely, halving the annual number of residential places would reduce the annual non-health-care cost of managing bipolar disorder by $39 \%$. The annual non-health-care cost attributable to bipolar disorder is also sensitive to the assumptions pertaining to the use of the criminal justice system by people with bipolar disorder. If people with bipolar disorder made twice as much use of the criminal justice system as the general population, the annual non-health-care cost of managing bipolar disorder would increase by $91 \%$. Conversely, if people with bipolar disorder made half as much use of the criminal justice system as the general population, the annual non-health-care cost of managing bipolar disorder would decrease by $45 \%$. However, the annual non-healthcare cost of managing bipolar disorder is not sensitive to changes in the annual number of non-NHS day care attendances.

\section{Indirect costs}

Sensitivity analyses (Table 8) showed that doubling of the annual number of unemployed people with bipolar disorder would lead to an $83 \%$ increase in the annual indirect cost attributable to bipolar disorder. Conversely, a $50 \%$ reduction in the annual number of unemployed people would lead to a $43 \%$ decrease in the annual indirect cost attributable to bipolar disorder. However, the annual indirect cost attributable to bipolar disorder is not sensitive to changes in the excess rate of absenteeism from work or in the annual number of suicides.

\section{DISCUSSION}

Cost of illness studies provide information about patterns of resource use associated with a particular condition, thereby enabling a greater understanding of the framework in which decisions about resource allocation are made. However, cost of illness studies, unlike cost-effectiveness and cost utility studies, are unable to directly inform decisions about the effective allocation of resources to fund particular treatments or strategies.

\section{Uncertainty}

In this analysis there is considerable uncertainty surrounding the prevalence of bipolar disorder in the UK because of the lack of robust epidemiological surveys. Community-based psychiatric surveys in other countries estimate the total prevalence of bipolar disorder to be $1.0-2.5 \%$, which is substantially higher than the number of people treated for bipolar disorder (Bebbington \& Ramana, 1995). Also, there may be a high level of unmet need, although some patients may develop coping strategies or endure symptoms below the thresholds for treatment, given the current risk-benefit ratios of available drugs. Finally, the variation in diagnostic threshold can contribute to the uncertainty surrounding the prevalence of bipolar disorder (Akiskal, 1996).

This analysis used interviews with psychiatrists and managers of day care facilities to estimate the percentage of their workload that was associated with managing people with bipolar disorder. In the hierarchy of evidence, such expert opinion is the least reliable compared with, for example, randomised control trials (Stevens \& Raftery, 1994), but in the absence of relevant published data this was the only suitable method with which to model these resource items. However, the estimated percentage of psychiatric out-patient workload and CMHT workload attributable to bipolar disorder was comparable to that reported by others (Onyett et al, 1995; National Health Service in Scotland, 1999).

The prevalence of bipolar disorder among patients in the DIN-link database was about $0.25 \%$. This was comparable with the $0.5 \%$ prevalence assumed in our study (Bebbington \& Ramana, 1995). However, some patients may be managed almost exclusively in secondary care, whereas others may not receive any health care. Furthermore, some people with bipolar disorder may have been misdiagnosed under a Read code that was not included in the DIN-link data-set. The estimated prevalence of people with bipolar disorder who attend psychiatric out-patient services 
is between 0.12 and $0.24 \%$, although the proportion of these patients in contact with their GP is unknown.

\section{Sensitivity}

The annual health care cost attributable to bipolar disorder is most sensitive to changes in the number of hospital admissions and CMHT contacts. However, there is little uncertainty about the annual number of hospital admissions, which was derived from statutory Department of Health returns, although some people with bipolar disorder may have been excluded from our analysis, such as those who have only one manic episode not followed by a depressive episode. The estimated cost of CMHT contacts made use of the survey by Onyett et al (1995), which examined the organisation and operation of CMHTs in England. The structure of CMHTs may have changed since this survey was performed, but we were unable to find more recent published data on the structure of CMHTs to inform our analysis. Therefore, there remains some uncertainty surrounding the cost of CMHT contacts pertaining to bipolar disorder. The annual nonhealth-care cost attributable to bipolar disorder is most sensitive to changes in the number of residential places. However, there is little uncertainty about the annual number of residential places, which was derived from a database used in a study by Chisholm (D. Chisholm, personal communication, 1999). The annual nonhealth-care cost is also sensitive to changes in the assumptions about the number of contacts made by people with bipolar disorder with the criminal justice system. A Swiss study suggested that people with bipolar disorder were between two and three times more likely to engage in criminal activity than the general population (Modestin et al, 1997). However, we found no evidence suggesting an increased risk of imprisonment among people with bipolar disorder in the UK. This discrepancy is worthy of further investigation.

The annual indirect cost attributable to bipolar disorder was sensitive to changes in the number of unemployed people, which was based on a survey of those in the Manic Depression Fellowship. However, the membership of the Fellowship may not be representative of all people with bipolar disorder. The baseline indirect costs in our study relate to people receiving treatment for bipolar disorder. Including untreated cases could substantially increase the indirect costs. However, because such people have not presented to the medical services, they may not exhibit the same level of morbidity and mortality as those who do present. Nevertheless, they may still endure reduced functioning and accrue costs.

We estimated that 640 people with bipolar disorder commit suicide annually. This is equivalent to about $11 \%$ of the 5905 suicides in the UK per year (Ray et $a l, 1998)$. Additionally, in one survey of people with bipolar disorder, $47 \%$ reported at least one attempted suicide (Gareth Hill, et al, 1996). In comparison, the annual number of deaths because of depression was estimated to be 2600 (Gareth Hill et al, 1996).

\section{Study limitations}

Primary care resource use was based on the DIN-link database. However, limitations in diagnostic categories may mean that some patients included in the data-set may have been suffering from unipolar psychosis. Nevertheless, it was assumed that all patients with a diagnostic code of 'affective psychosis' suffer from bipolar disorder. Furthermore, patients with other conditions, such as schizophrenia and schizoaffective disorder, may have been included under the diagnostic categories for 'mania and hypomania', reflecting the difficulties in making a differential diagnosis for this disorder.

The cost of drugs used to treat bipolar disorder constitutes less than $2 \%$ of the total cost of GP prescribing for all psychiatric conditions (Department of Health, 2000d) and about $5 \%, 14 \%$ and $14 \%$ of general psychiatric in-patient, out-patient and general community team costs, respectively (Department of Health, 2000d). Treatment choices are particularly important in patients with bipolar disorder where compliance with conventional maintenance treatment is low (Keck et al, 1997). Some atypical antipsychotics have been shown to have antimanic properties (Tohen \& Grundy, 1999; Keck et al, 2000) and a lower risk of extrapyramidal symptoms than is associated with typical antipsychotics (Miller et al, 2001), potentially leading to improved compliance. The cost of drugs prescribed by psychiatrists in out-patient clinics has not been included in the present analysis. However, because most drugs are prescribed and dispensed in the community, this is unlikely to lead to a substantial difference in the annual drug cost. Moreover, the estimated annual primary care drug cost of $£ 8.5$ million for people with bipolar disorder is small compared, for example, with the drug costs for schizophrenia for England in 1992/93. These were estimated to be about $£ 32$ million ( $£ 39$ million at $1999 / 2000$ prices) (Knapp, 1997).

A number of services have not been costed in this study, including a work rehabilitation scheme provided by the NHS, referrals to either a psychotherapist or clinical psychologist and attendances at a drug or alcohol dependency service. The associated costs of these are likely to be proportionally very low and within our sensitivity analyses. All these services are provided within the NHS and form part of the care provided by out-patient clinics, CMHTs or day hospitals, and our baseline estimates are likely to include some of these costs. The analysis also excluded the intangible costs of patients and their families. The psychological burden of living with bipolar disorder and its disruptive effect on daily living affects the usual activity of patients and their families (Onyett et al, 1995). Such activity may not involve paid employment and is difficult to quantify.

\section{Comparison with schizophrenia}

Compared with schizophrenia, bipolar disorder is a neglected disease. This is true if one compares research output in academic journals on the one hand and NHS planning documents on the other. The present study illustrates that bipolar disorder costs less than schizophrenia: $£ 2$ billion compared with $£ 3.7$ billion at $1999 / 2000$ prices. In-patient care for schizophrenia accounts for over $90 \%$ of the annual direct health care cost ( $£ 864$ million at $1999 / 2000$ prices) (Knapp, 1997), which was substantially higher than the $35 \%$ of the annual direct health care cost ( $£ 69$ million) attributable to in-patient care associated with bipolar disorder in our study. Allowing for the difference in time between the two studies, this difference suggests that, despite being possibly related conditions (Goodwin \& Jamison, 1990; Maziade et al, 1995), treatment patterns differ substantially.

\section{ACKNOWLEDGEMENTS}

The authors thank the following psychiatrists and managers of non-NHS day care centres for their contributions to the study: Dr I. Akhter, Small Heath Mental Health Unit, Birmingham; Dr C. Anderson, The Dukes Priory Hospital, Chelmsford; Dr T. Bullock, Ealing Hospital, London; Dr C. Gillespie, Newton Abbott Hospital, Torquay; Professor G. Goodwin, Warneford Hospital, Oxford; Professor 
S. Martin, Cherry Knowle Hospital, Sunderland; Dr J. Meehan, South Kensington and Chelsea Mental Health Unit, London; Dr A. Suri, Clatterbridge Hospital, The Wirral; Dr T. Turner, Homerton Hospital, London; Professor A. Young, The Royal Victoria Infirmary, Newcastle upon Tyne; Ms D. Finch, Westminster AMH, London; Ms M. Fisher, Castle Day Centre, Southwark, London; Ms M. Naughton, Beech Croft Day Centre, Birmingham; Mr P. Nevis, Islington Mind, London; Ms G. Newlon, Carpentry Instructor, Pine Street Day Centre, Clerkenwell, London; Ms J. Sahin, Delacey House, Leeds; Ms H. Taylor, Homerton Drop In Centre, London.

The authors also thank Janssen-Cilag for their support of this study.

\section{REFERENCES}

Akiskal, H. S. (1996) The prevalent clinical spectrum of bipolar disorders: beyond DSM-IV. Journal of Clinical Psychopharmacology, 16 (suppl. I), 4S-14S.

Bebbington, P. \& Ramana, R. (1995) The epidemiology of bipolar affective disorder. Social Psychiatry and Psychiatric Epidemiology, 30, 279-292.

Department of Health (1998) Community care statistics 1997. Day and domiciliary personal social services for adults, England. Statistical Bulletin, $\mathbf{3}$.

- (1999a) NHS Day Care Facilities, England, Financial Year 1998-99. London: Department of Health.

- (1999b) Outpatients and Ward Attenders, England.

Financial Year 1998-99. London: Department of Health.

- (2000a) Hospital Episode Statistics 1998-99. London: Department of Health.

- (2000b) Personal Social Services. Current Expenditure in England: 1998-99. London: Department of Health.

- (2000c) The Government Expenditure Plans, 2000-

2001. London: Department of Health.

- (2000d) Prescriptions dispensed in the community. Statistics for 1989 to 1999, England. Statistical Bulletin, 20

Drummond, M. F., O'Brien, B. J., Stoddart, G. L., et al (1998) Cost benefit analysis. In Methods for the Economic Evaluation of Health Care Programmes, pp. 205-231. Oxford: Oxford University Press.

\section{Gareth Hill, R., Hardy, P. \& Shepherd, G. (1996)}

Perspectives on Manic Depression. A Survey of the Manic Depression Fellowship. London: Sainsbury Centre for Mental Health.

Goodwin, F. K. \& Jamison, K. R. (1990) ManicDepressive Illness. New York: Oxford University Press.

Gunn, J., Maden, A. \& Swinton, M. (1991) Mentally Disordered Prisoners. London: Home Office.

Haymarket Publications (2000) Monthly Index of Medical Specialties (MIMS), March 2000 edition. London: Haymarket Publications.

Keck, P. E., Jr., McElroy, S. L., Strakowski, S. M., et al (1997) Compliance with maintenance treatment in bipolar disorder. Psychopharmacology Bulletin, 33, 87-91.

$\ldots, \ldots, \ldots$, et al (2000) Antipsychotics in the treatment of mood disorders and risk of tardive dyskinesia. Journal of Clinical Psychiatry, 61 (suppl. 4), 33-38.

Kind, P. \& Sorensen, J. (1993) The costs of depression. International Clinical Psychopharmacology, 7, 191-195.

Knapp, M. (1997) Costs of schizophrenia. British Journal of Psychiatry, I7I, 509-518.

Lepine, J. P., Gastpar, M., Mendlewicz, J., et al (1997) Depression in the community: the first pan-European

\section{CLINICAL IMPLICATIONS}

- The annual National Health Service cost of managing bipolar disorder could be reduced if more patients were managed in the community rather than in secondary care.

- Reducing the use of typical antipsychotics in favour of atypical antipsychotics may reduce non-compliance with prescribed medication, resulting in improved management of patients.

- Optimising patients' treatment may improve their social and occupational functioning, thereby reducing the societal cost of bipolar disorder.

\section{LIMITATIONS}

- Cost of illness studies are unable to directly inform decisions about the effective allocation of resources to fund particular treatments or strategies.

- There is uncertainty surrounding the prevalence of bipolar disorder in the UK.

- There is uncertainty surrounding some of the resource use estimates used in the analysis.

ROBEN DAS GUPTA, MSc, JULIAN F. GUEST, PhD, CATALYST Health Economics Consultants, Northwood, Middlesex

Correspondence: Dr Julian F. Guest, CATALYST Health Economics Consultants, 34b High Street, Northwood, Middlesex HA6 IBN, UK. Tel: +44 (0) 1923450 045; Fax: +44 (0) 1923450046 e-mail: jg.catalyst@dial.pipex.com

(First received 8 March 200I, final revision 12 September 200I, accepted 27 September, 200I)

study DEPRES (Depression Research in European Society). International Clinical Psychopharmacology, I2, 19-29.

Martin, R. M. (1995) The doctors independent network database: background and methodology. Pharmaceutical Medicine, 9, 165-176.

Maziade, M., Roy, M.-A., Martinez, M., et al (1995) Negative psychoticism, and disorganized dimensions in patients with familial schizophrenia or bipolar disorder: continuity and discontinuity between the major psychoses. American Journal of Psychiatry, 152, 1458-1463.

\section{Miller, D. S., Yatham, L. N. \& Lam, R.W. (200I)}

Comparative efficacy of typical and atypical antipsychotics as add-on therapy to mood stabilizers in the treatment of acute mania. Journal of Clinical Psychiatry, 62, 975-980.

Modestin, J., Hug, A. \& Ammann, R. (1997) Criminal behavior in males with affective disorders. Journal of Affective Disorders, 42, 29-38.

National Health Service in Scotland (1999) Scottish Health Statistics 1998. Information and Statistics Division, $\mathrm{NHS}$ in Scotland.

Netten, A., Dennett, J. \& Knight, J. (1999) Unit Costs of Health and Social Care 1999. University of Kent, Canterbury: Personal Social Services Research Unit.

Office for National Statistics (1995) Morbidity Statistics from General Practice. 4th National Study, 1991-92, Series MB5 No. 3. London: Office for National Statistics.
(2000) Annual Abstract of Statistics. London: Office for National Statistics.

Onyett, S., Heppleston, T. \& Bushnell, D. (1995) The Organization and Operation of Community Mental Health Teams in England. A National Survey. London: Sainsbury Centre for Mental Health.

Ray, S., Borton, E. \& Coyles, L. (1998) Listen Up Responding to People in Crisis. London: The Samaritans.

Regier, D. A., Farmer, M. E., Rae, D. S., et al (1990) Comorbidity of mental disorders with alcohol and other drug abuse. Results from the Epidemiologic Catchment Area (ECA) study. Journal of the American Medical Association, 264, 2511-2518.

Sharma, R. \& Markar, H. R. (1994) Mortality in affective disorder. Journal of Affective Disorders, 31, 91-96.

Stationery Office (2000a) The Government's Annual Report, 1999/2000. London: Stationery Office.

- (2000b) Drug Tariff May 2000. London: Stationery Office.

Stevens, A. \& Raftery, J. (1994) Introduction. In Health Care Needs Assessment. The Epidemiologically Based Needs Assessment Reviews (eds A. Stevens \& J. Raftery), Vol. I, pp. II-30. Oxford: Radcliffe Medical Press.

Tohen, M. \& Grundy, S. (1999) Management of acute mania. Journal of Clinical Psychology, 60, 31-34.

World Health Organization (1992) Tenth Revision of the International Classification of Diseases and Related Health Problems (ICD-10). Geneva: WHO. 